\title{
DUNE EROSION PHYSICAL, ANALYTICAL AND NUMERICAL MODELLING
}

\author{
Felice D’Alessandro ${ }^{1}$, Giuseppe Roberto Tomasicchio ${ }^{1}$, Fausta Musci ${ }^{1}$ and Andrea Ricca ${ }^{2}$
}

\begin{abstract}
The present paper provides an overview of the large-scale physical model experiments performed at the Canal d'Investigaciò i Esperimentaciò Marìtima (CIEM), Laboratori d'Enginyeria Marìtima (LIM), Universitat Politècnica de Catalunya (UPC), Barcelona, within the EU-Hydralab III Integrated Infrastructure Initiative. The model tests have been carried out in a flume with a sandy dune exposed to a combination of water levels and wave conditions. Different regimes of wave attacks on the sandy/beach dune system have been investigated; in particular, the study provides a unique set of large-scale physical data concerning the storm waves induced dune overwash (Tomasicchio et al. 2011a; Tomasicchio et al.2011b). The effects of various "load parameters" on the dune erosion process generation, including dune recession rates in terms of the retreat of the dune face, $\Delta x$, and the eroded volume, $\Delta V$, have been investigated and discussed. The laboratory data sets have been adopted to calibrate and verify the analytical model proposed by Larson et al. (2004) in order to calculate the values of $\Delta V$ at specific time intervals. Furthermore, the profile measurements have been used to calibrate and verify the numerical model C-SHORE (Kobayashi et al. 2007) predicting the beach-dune profile modifications over the near-shore region (Tomasicchio et al. 2011a; Tomasicchio et al.2011b).
\end{abstract}

Keywords: dune erosion; overwash; large-scale experiment; numerical model; analytical model

\section{INTRODUCTION}

Coastal dunes generally constitute the natural barrier protecting areas along many of the world's sandy coastlines against high waves and water levels during severe storms. The need for predicting the response of coasts to storms is rising steadily as the population in coastal areas grows worldwide and loads on coastal systems increase due to rising sea levels and the possibility of more intense storms (Emanuel et al. 2008). Thus, it is of significant value for coastal engineers to be able to predict the impact of a storm on a dune in terms of recession distance, eroded volume, overwash rate and probability of breaching. In the recent years different numerical models, of time-dependent and timeaveraged type, have been developed for these purposes (e.g. Kobayashi et al. 2007). As an alternative to numerical models, analytical models typically require marked simplifications in the description of the governing processes, forcing, and initial and boundary conditions, whereas numerical models can deal with these aspects with less restrictions. However, analytical models offer advantages since the simplicity make them easy to apply, which is valuable in the initial stage of a project when approximate estimates are required.

Sallenger et al. (2003) describes four regimes of storm attack on a beach/dune system:

1. swash regime with wave run-up confined to the foreshore;

2. collision regime with swash and run-up to the dune face;

3. overwash regime with wave overtopping the dune crest;

4. breaching and inundation regime.

With regard to the collision regime, experiments on dune erosion using large-scale models have been performed by Vellinga (1986), Delft Hydraulics (1982a,b, 1984a,b, 1987, 2004, 2006, 2007), Van Gent et al. (2008). Similar experiments have been done in Germany (Dette et al. 1998) focusing on German coastal conditions and in the USA (Kraus and Smith 1994) focusing on USA coasts. The experiments performed in the past were generally focused on the investigation of the seaward profile development and morphodynamics processes under given wave and water level conditions. However, for the case of the earlier experiments (Delft Hydraulics 1982a,b, 1984a,b, 1987; Vellinga 1986, Dette et al. 1998, Kraus and Smith 1994), the instrument deployment was generally restricted to the surf zone and wave periods did not cover the range of interest (van Thiel de Vries et al. 2008). The more recent large-scale Deltaflume experiments (Delft Hydraulics 2004, 2006, 2007; van Gent 2008) focused on extreme storm conditions and instrument deployment was in close proximity of the dune face to better examine the dune erosion processes (van Thiel de Vries et al. 2008). These experiments, however, did not include the overwash transport observations although accurate modelling of the wave overwash processes has to be considered essential in predicting dune profile evolution during storm events.

\footnotetext{
${ }^{1}$ Department of Engineering, University of Salento, via Monteroni ECOTEKNE, 73100 Lecce, Italy

${ }^{2}$ Department for Soil Conservation, University of Calabria, ponte P. Bucci cubo 42/B, 87036 Arcavacata di Rende, Italy
} 
When extreme waves attack the beach, they often have enough energy to overtop the dune crest and create landward transport of water and sediment. The dune may erode rapidly and the lowering of the dune crest may lead in wave overtopping and overwash. In this view, predicting beach profile changes and overwash accurately is really important for effective flood risk assessment, sustainable development of coastal areas and engineering design of beach nourishment projects (USACE 2003), especially in prospective of sea level rise. Donnelly et al. (2006) classified different overwash scenarios and gave a comprehensive overview of the current state of knowledge and related field, laboratory and numerical studies. In particular, with regard to physical model experiments it should be emphasized that relatively few small-scale laboratory studies on dune overwash have been conducted (Hancock 1994, Hancock and Kobayashi 1994, Kobayashi et al. 1996, Figlus et al. 2011) and comprehensive large-scale physical and field data sets are still lacking.

The limitations found in literature triggered an experimental investigation aimed at creating a unique set of large-scale physical data pertaining to wave-induced overwash of dunes. In particular, the main purposes of the experiments were to:

- observe and analyze different regimes of wave-dune interaction: collision, overwash and breaching (Sallenger et al. 2003);

- investigate the effect of various "load parameters", namely $H_{\mathrm{s}, 0}=$ off-shore significant wave height, $T_{\mathrm{p}}=$ peak wave period, $s_{\mathrm{p}}=$ peak wave steepness, $h_{0}=$ off-shore water depth, $C_{r}=$ reflection coefficient, type of breaking on the dune erosion process generation, including dune recession rates in terms of $\Delta x$ and $\Delta V$;

- create a reliable and accurate data set for analytical and numerical modeling calibration and verification;

- obtain new empirical formulas for suspended and bedload transport rates in the wet and dry zone for the case of major overwash.

\section{SET-UP OF THE PHYSICAL MODEL AND WAVE CONDITIONS}

The physical model tests have been performed at the CIEM wave flume of LIM/UPC in Barcelona. The CIEM wave flume is $100 \mathrm{~m}$ long, $3 \mathrm{~m}$ wide and $5 \mathrm{~m}$ deep. The initial cross-shore profile (Figure 1) was inspired by the down-scaled beach profile at "Canto do Marco", north of Figueira da Foz, along the Atlantic coast of Portugal. The scale length was 1:4.8. The horizontal coordinate, $x$, has been taken to be positive onshore with $x=0$ at the wave paddle. The crest of the dune was $2 \mathrm{~m}$ long and the seaward and landward slopes were 1:2.30. The sand in the flume had a mean diameter, $d_{50}$, equal to $0.246 \mathrm{~mm}$ with measured fall velocity, $w_{\mathrm{f}}$, of $34 \mathrm{~mm} / \mathrm{s}$.
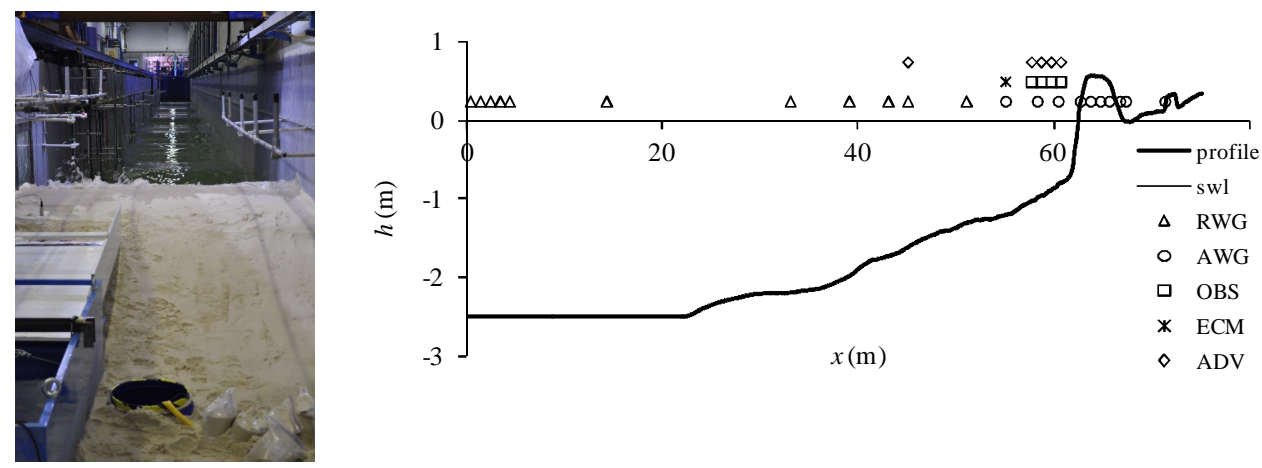

Figure 1. As built cross shore profile and instrument positions.

A wedge-type wave paddle has been used to generate irregular waves, based on a Jonswap spectrum with peak enhancement factor, $\gamma$, equal to 3.3. Two different values of $h_{0}$ have been considered in the flume: $h_{0}=2.35 \mathrm{~m}$ and $h_{0}=2.50 \mathrm{~m}$; as a consequence, two different freeboards, $R$, have been adopted. The experimental set-up resembles the scenario of a beach-dune system with no berm foreshore and a sudden increase of water level.

A total of 9 tests have been considered; the initial beach geometry was rebuilt at the end of each test. Wave conditions have been selected in order to investigate the influence of different "load parameters" on the dune erosion rate. As an example, for given values of $H_{\mathrm{s}, 0}$ and $h_{0}$, Test $\mathrm{D} v s \mathrm{E} v s \mathrm{~F}$ 
show the influence of $T_{\mathrm{p}}$ on the dune erosion rate (van Gent et al. 2008). The hydrodynamic conditions for each test are summarized in Table 1 (Tomasicchio et al. 2011a).

\begin{tabular}{|l|l|l|l|l|l|l|l|}
\hline \multicolumn{7}{|c|}{ Table 1. Tests programme with wave conditions at wave paddle. } \\
\hline$h_{0}$ & $R(\mathrm{~m})$ & Test & $H_{\mathrm{s}, 0}(\mathrm{~m})$ & $T_{\mathrm{p}}(\mathrm{s})$ & $s_{\mathrm{p}}$ & Duration & Key findings \\
\hline 2.35 & 0.65 & $\mathrm{~A}$ & 0.25 & 2.5 & 0.026 & 4500 & Collision regime \\
& & $\mathrm{B}$ & 0.30 & 2.5 & 0.031 & 4500 & Collision regime \\
& & $\mathrm{C}$ & 0.30 & 3.0 & 0.021 & 5400 & Minor overwash - collision regime \\
& & $\mathrm{D}$ & 0.33 & 2.5 & 0.034 & 4500 & Collision \\
& & $\mathrm{E}$ & 0.33 & 3.0 & 0.024 & 5400 & Minor overwash - collision regime \\
& & $\mathrm{F}$ & 0.33 & 3.5 & 0.017 & 6300 & Major overwash - collision regime \\
& 0.35 & $\mathrm{G}$ & 0.25 & 2.5 & 0.026 & 4500 & Collision \\
& & $\mathrm{H}$ & 0.30 & 2.5 & 0.031 & 4500 & Minor overwash - collision regime \\
& & $\mathrm{I}$ & 0.33 & 3.0 & 0.024 & 600 & Major overwash - collision regime \\
\hline
\end{tabular}

Measurements of water surface elevation, flow velocities and sediment concentration along the flume have been carried out during each test (Figure 1). In particular, 11 resistant wave gauges (RWG) and 4 acoustic wave gauges (AWG Long Range) have been used to measure time series of the free surface elevation above the still water level (SWL); 5 out of a total of 11 RWG were installed centered around $x=2.30 \mathrm{~m}$ to separate incoming and dune-reflected waves; 5 Acoustic Doppler Velocimeter (ADV) have been used to measure fluid velocities in the water column; 8 Optical Backscatter Sensor (OBS) have been displaced at 4 transects where velocity measurements were conducted, allowing correlation between the velocity and concentration observations; 4 spherical S-type Electromagnetic Current Meter (ECM), vertically installed along the entire water depth at a fixed transect in the flume around $x=55 \mathrm{~m}$, measured instantaneous velocity profiles induced by a breaking wave (Tomasicchio 2004, D'Alessandro and Tomasicchio 2008). The duration of a single test was divided into different wave attacks each composed by $n$ waves with $n=250,250,250,500,1000$ and 1000 , respectively. After each interval, the test was interrupted to perform profile measurements along the longitudinal flume axis by means of a mechanical profiler. With the scope to evaluate topographic changes due to overwash action on the emerged part of the dune photogrammetric surveys have been also carried out. High resolution digital SLR cameras and close-range photogrammetry software have been used to produce digital elevation models (DEMs). Time variation of overtopping volumes has been measured by means of a tank displaced at the rear side of the dune and equipped with a pump and a sensor inside to monitor the water level. On the top of it, a sediment trap has been placed fixed to a weight measuring system. The temporal variation of the sediment load has been measured. The overtopping tank has been also equipped with a wooden board to leave the water reach the recipient. Information on the flow thickness of the overtopping tongue have been obtained by using 3 acoustic wave gauges (AWG Medium Range) which have been installed, with a vertical distance of $25 \mathrm{~cm}$ from the crest of the dune, from the front side (seaward) to the rear side (landward) of the crest. Finally, 5 pressure cells have been buried in the dune. The pressure cells gave information about the pressure of the overtopping tongue. The interested reader is referred to Tomasicchio et al. (2011a) for a detailed description of the physical model set-up.

\section{DUNE EROSION: "CAUSES AND EFFECTS"}

A preliminary analysis on the mechanism of "causes and effects" concerning the wave storm induced dune erosion is presented. In particular, the time variation of the dune profile under a given wave attack and its dependency on wave height, wave period and storm surge level has been investigated.

By considering as "effects" the observed values of $\Delta x$ and $\Delta V$ determined by the hydrodynamic "load parameters": $T_{\mathrm{p}}, H_{\mathrm{s}, 0}, h_{0}$ ("causes"), the following questions are addressed:

1. Does $T_{\mathrm{p}}$ influence $\Delta x$ and $\Delta V$ ?

2. Does $h_{0}$ influence $\Delta x$ and $\Delta V$ ?

3. Does $H_{\mathrm{s}, 0}$ influence $\Delta x$ and $\Delta V$ ?

A particular selection of the wave conditions in the test programme, summarized in the Table 1, allows to provide answers to the question above.

Figure 2 (a) shows the variation of $\Delta x$ with $n$ for each test. It appears evident that $\Delta x=f(n)$ presents a different behaviour in the two intervals: $n<500$ and $n>500$, respectively; the larger values of 
$\Delta x$ have been observed during the first wave attack with $n=250$; in this case, a percentage (\%) of dune recession distance in the range between 22.5 to 52.5 has been obtained (Figure 2 (b)). A motivation for this behaviour can be found in the assumed experimental set-up which determines the direct wave breaking at the steep dune. When the phenomenon is in progress, as a consequence of the formation of scarping at the toe of the dune, the incoming breaking waves impacting with the outgoing reflected broken waves (wave "collision") generate a large amount of turbulence. A certain volume of sand is picked up by swash and surf zone processes that move the sediment seaward to form a bar/step which, gradually, moves back the wave breaking respect to the initial condition. Furthermore, it is noticed that, with reference to the first wave attack $(n=250)$, the largest values of $\Delta x$ have been observed at overwash conditions (Tests H, F, C). Minor or major overwash occurred only at the first 250 waves because, after the initial profile changes, intense wave breaking occurred on the formed bar/step; the dune slope affected by breaking waves was reduced and a lower run-up did not allow wave overtopping.

(a)

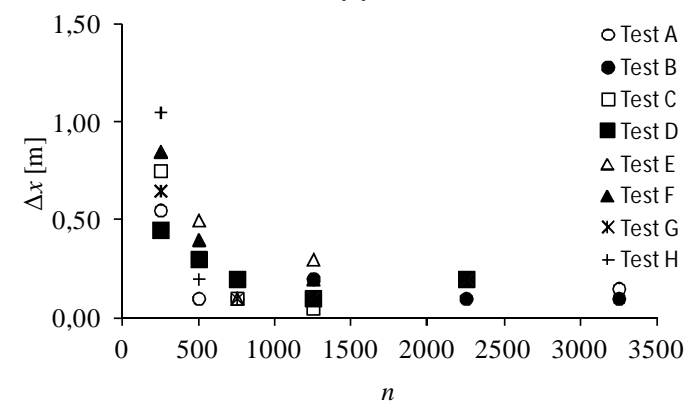

(b)

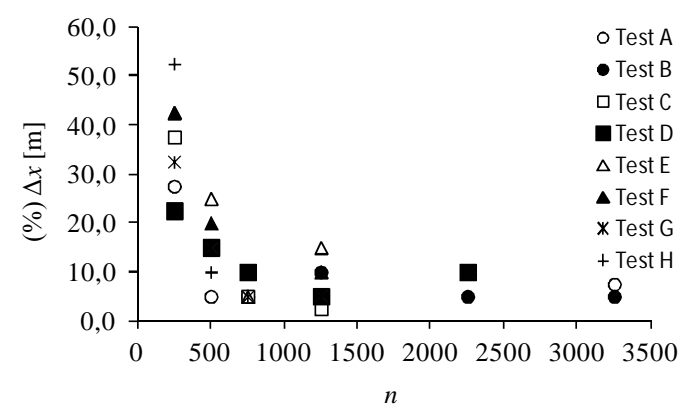

Figure 2. (a) Variation of $\Delta x=f(n)$. (b) Variation of $\Delta x(\%)=f(n)$.

Figures 3 (a) and (b) show the comparison between the values of $\Delta x=f(n)$ and $\Delta V=f(n)$, respectively, observed during Test B $\left(T_{\mathrm{p}}=2.5 \mathrm{~s}\right)$ and Test $\mathrm{C}\left(T_{\mathrm{p}}=3.0 \mathrm{~s}\right)$, kept constant $H_{\mathrm{s}, 0}$ and $h_{0}$. The results indicate that $T_{\mathrm{p}}$ influences $\Delta x$ and $\Delta V$; in particular, $\Delta x$ and $\Delta V$ increase for larger values of $T_{\mathrm{p}}$ in accordance with van Gent et al. (2008). More in detail, the influence of $T_{\mathrm{p}}$ on $\Delta x$ and $\Delta V$ is evident after the first wave attack; for $n$ larger than 250, the observed values of $\Delta x$ and $\Delta V$ are quite similar. Furthermore, it is noticed that, during the first wave attack, Test $\mathrm{C}$ and Test $\mathrm{B}$ presented different regimes of wave-dune interaction: overwash conditions for the case of Test $\mathrm{C}$ and collision regime for the case of Test B.

(a)

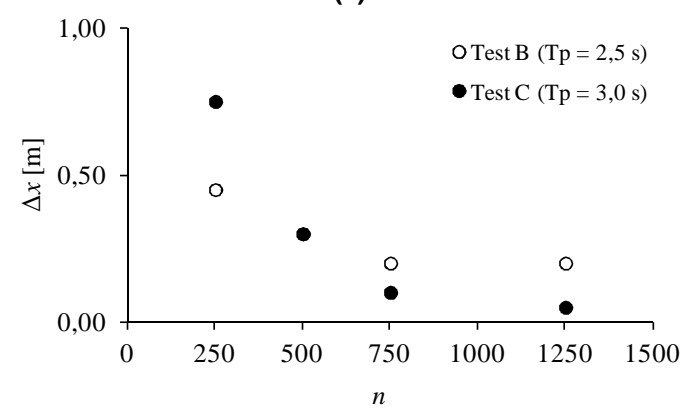

(b)

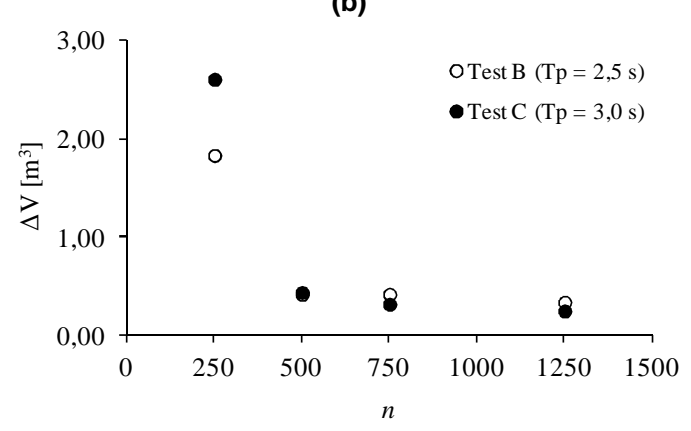

Figure 3. Influence of $T_{\mathrm{p}}$ on (a) $\Delta x=f(n)$ and (b) $\Delta V=f(n)$.

Figures 4 (a) and (b) show the comparison between the values of $\Delta x=f(n)$ and $\Delta V=f(n)$, respectively, observed during Test B $\left(h_{0}=2.35 \mathrm{~m}\right)$ and Test $\mathrm{H}\left(h_{0}=2.50 \mathrm{~m}\right)$, kept constant $H_{\mathrm{s}, 0}$ and $T_{\mathrm{p}}$. The results indicate that the storm surge influences $\Delta x$ and $\Delta V$; in particular, $\Delta x$ and $\Delta V$ increase for larger values of $h_{0}$. Also in this case, as previously found in Figure 3, the influence of $h_{0}$ on $\Delta x$ and $\Delta V$ is evident after the first 250 waves; for $n$ larger than 250, the observed values of $\Delta x$ and $\Delta V$ present a similar behaviour. In addition, by analogy with Figure 3, the observed larger values of $\Delta x$ and $\Delta V$ correspond to the occurrence of different regimes of wave-dune interaction: overwash conditions for the case of Test $\mathrm{H}$ and collision regime for the case of Test $\mathrm{B}$. 
(a)

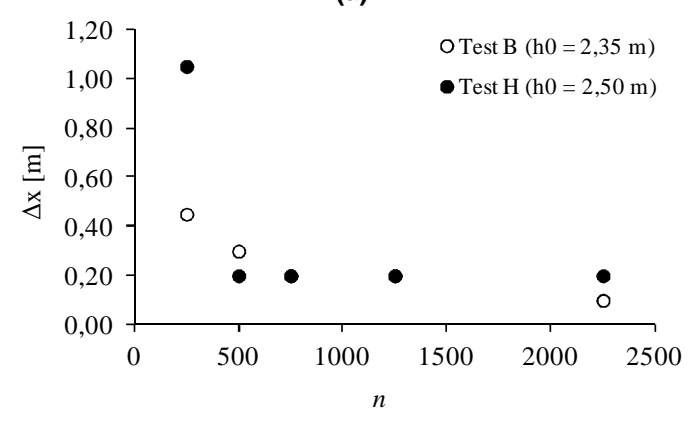

(b)

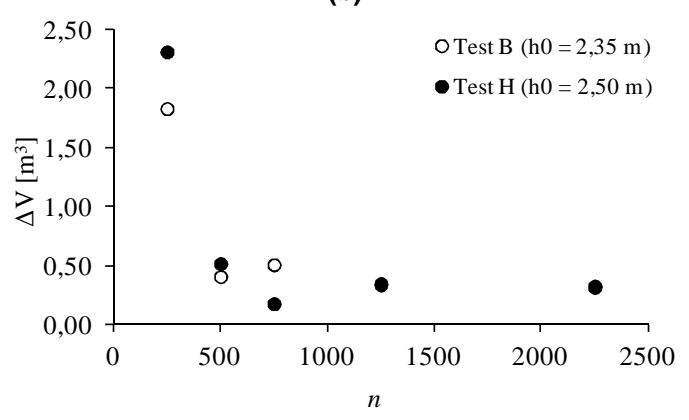

Figure 4. Influence of $h_{0}$ on (a) $\Delta x=f(n)$ and (b) $\Delta V=f(n)$.

THE ANALYTICAL MODEL

Larson et al. (2004) proposed a simple yet physically based analytical model of dune erosion for preliminary estimates of $\Delta x$ and $\Delta V$ under severe wave storms attacks. By combining the transport relationship based on "impact theory" with the sediment volume conservation equation for the dune, an analytical solution is obtained if the geometrical, forcing and initial conditions are simple enough. The needed schematization of these conditions implied that an empirical coefficient appear in the solution with a value to be estimated on the basis of high-quality data sets on dune erosion from field and/or laboratory experiments. In this path, the large-scale physical data carried out during the Hydralab III project at LIM have been adopted.

\section{Theoretical developments}

A basic assumption in estimating dune erosion from "wave impact theory" is that there is a linear relationship between the impact (force of the bores impacting the dune), $F$, and the weight, $\Delta W$, of the sediment volume eroded from the dune (Fisher et al. 1986, Overton et al. 1987, Nishi and Kraus 1996). This may be written as:

$$
\Delta W=C_{\mathrm{E}} F
$$

where $C_{\mathrm{E}}$ is an empirical coefficient. The weight of $\Delta V$ can be also given by:

$$
\Delta W=\Delta V \rho_{\mathrm{s}}(1-p) g
$$

where $\rho_{\mathrm{s}}=$ density of sediment, $p=$ porosity and $g=$ acceleration due to gravity.

For a number of bores impacting the dune during a time period $\Delta t$, the total swash force may be written as:

$$
F=\frac{1}{2} \rho \frac{u_{0}^{4}}{g C_{\mathrm{u}}^{2}} \frac{\Delta t}{T}
$$

where $u_{0}=C_{\mathrm{u}} \sqrt{g h_{0}}$ is the speed of the bore, $h_{0}$ is the height of the bore and $C_{\mathrm{u}}$ is an empirical coefficient.

By equating $F$ and $\Delta W$, Eq. 2 and Eq. 3 gives:

$$
\Delta V \rho_{\mathrm{s}}(1-p) g=\frac{1}{2} C_{\mathrm{E}} \rho \frac{u_{0}^{4}}{g C_{\mathrm{u}}^{2}} \frac{\Delta t}{T}
$$

Some rearranging yields:

$$
\frac{\Delta V}{\Delta t}=\frac{1}{2} \frac{C_{\mathrm{E}}}{C_{\mathrm{u}}^{2}} \frac{\rho}{\rho_{\mathrm{s}}} \frac{u_{0}^{4}}{g^{2} T} \frac{1}{(1-p)}=C_{\mathrm{s}} \frac{u_{0}^{4}}{g^{2} T}
$$

with: 


$$
C_{\mathrm{s}}=\frac{1}{2} \frac{C_{\mathrm{E}}}{C_{\mathrm{u}}^{2}} \frac{\rho}{\rho_{\mathrm{s}}}
$$

In order to obtain an analytical solution, some simplifying assumptions are introduced. With regard to the value of $u_{0}$, it can be estimated as:

$$
u_{0}^{2}=u_{\mathrm{s}}^{2}-2 g z_{0}
$$

where $u_{\mathrm{s}}$ is the velocity of the bore as it starts its travel up to the foreshore, and $z_{0}$ is the elevation difference between the dune foot and the beginning of the swash.

By substituting Eq. 6 and Eq. 7 into Eq. 5, yields:

$$
\frac{\Delta V}{\Delta t}=C_{\mathrm{s}} \frac{\left(u_{\mathrm{s}}^{2}-2 g z_{0}\right)^{2}}{g^{2} T}
$$

With regard to $u_{\mathrm{s}}$, it can be expressed in terms of the run-up height, $R_{u}$. At the limit of the run-up, the velocity $u_{0}$ should be zero, implying that Eq. 7 with $z_{0}=R_{\mathrm{u}}$ and $u_{0}=0$ :

$$
u_{s}^{2}=2 g R_{\mathrm{u}}
$$

If the variation in $z_{0}$ with time is ignored, which may be appropriate when the retreat of the dune is small, thus Eq. 8 may be written:

$$
\frac{d V}{d t}=-4 C_{\mathrm{s}} \frac{\left(R_{\mathrm{u}}-z_{0}\right)^{2}}{T}
$$

For the case when $R_{\mathrm{u}}$ and $z_{0}$ are constants, the following solution is obtained:

$$
V=V_{0}-4 C_{\mathrm{s}}\left(R_{\mathrm{u}}-z_{0}\right)^{2} \frac{t}{T}
$$

\section{THE ANALYTICAL MODEL CALIBRATION AND VERIFICATION}

The $C_{\mathrm{s}}$ coefficient has been calibrated based on the observed values of $\Delta V$ at the end of the different wave attacks composing the entire test series:

$$
C_{s}=-\frac{1}{4} \frac{(\Delta V)_{\text {observed }}}{\left(R_{u}-z_{0}\right)^{2}} \frac{T}{t}
$$

Figure 5 shows the calculated values of $C_{\mathrm{s}}$ for each test, which has been plotted as function of $n$.

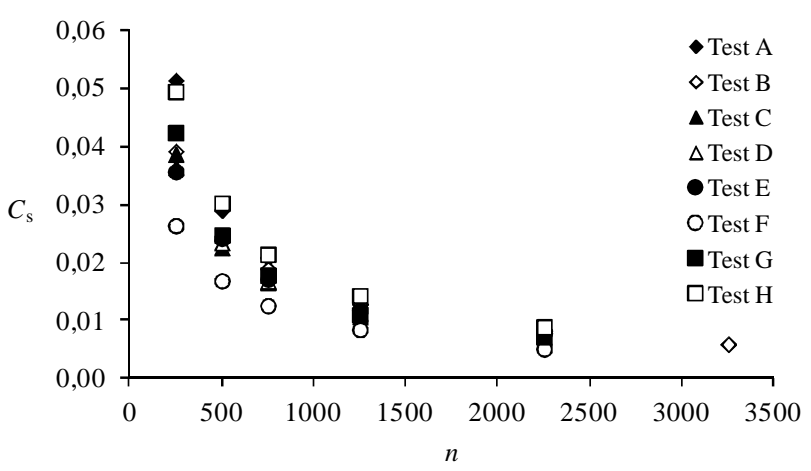

Figure 5. The empirical coefficient $C_{\mathrm{s}}=f(n)$.

The application of the Least Square Method has given: 


$$
C_{\mathrm{s}}=2.56 n^{-0.75}
$$

The estimated value of the determination coefficient, $R^{2}$, is equal to 0.93 .

With regard to the estimation of $R_{\mathrm{u}}$, in the present paper the Hunt (1959) formula has been adopted:

$$
R_{u}=0.158 \sqrt{H_{0} L_{0}}
$$

It is noticed that Eq. (14) neglects the influence of the beach slope. The inaccuracy due to this approximation decreases with the increase of dune erosion which determines a gentler bottom slope. The model proposed by Larson et al. (2004) in its original version consider bores up-rush on the foreshore impacting the dune; in this case, the foreshore profile changes are neglected. In the present study, the experimental set-up corresponds to $z_{0}=0.0 \mathrm{~m}$.

Figure 6 depicts the comparisons between the observed and calculated values of $\Delta V=f(n)$, for the selected tests as representative of the others, showing a good agreement.
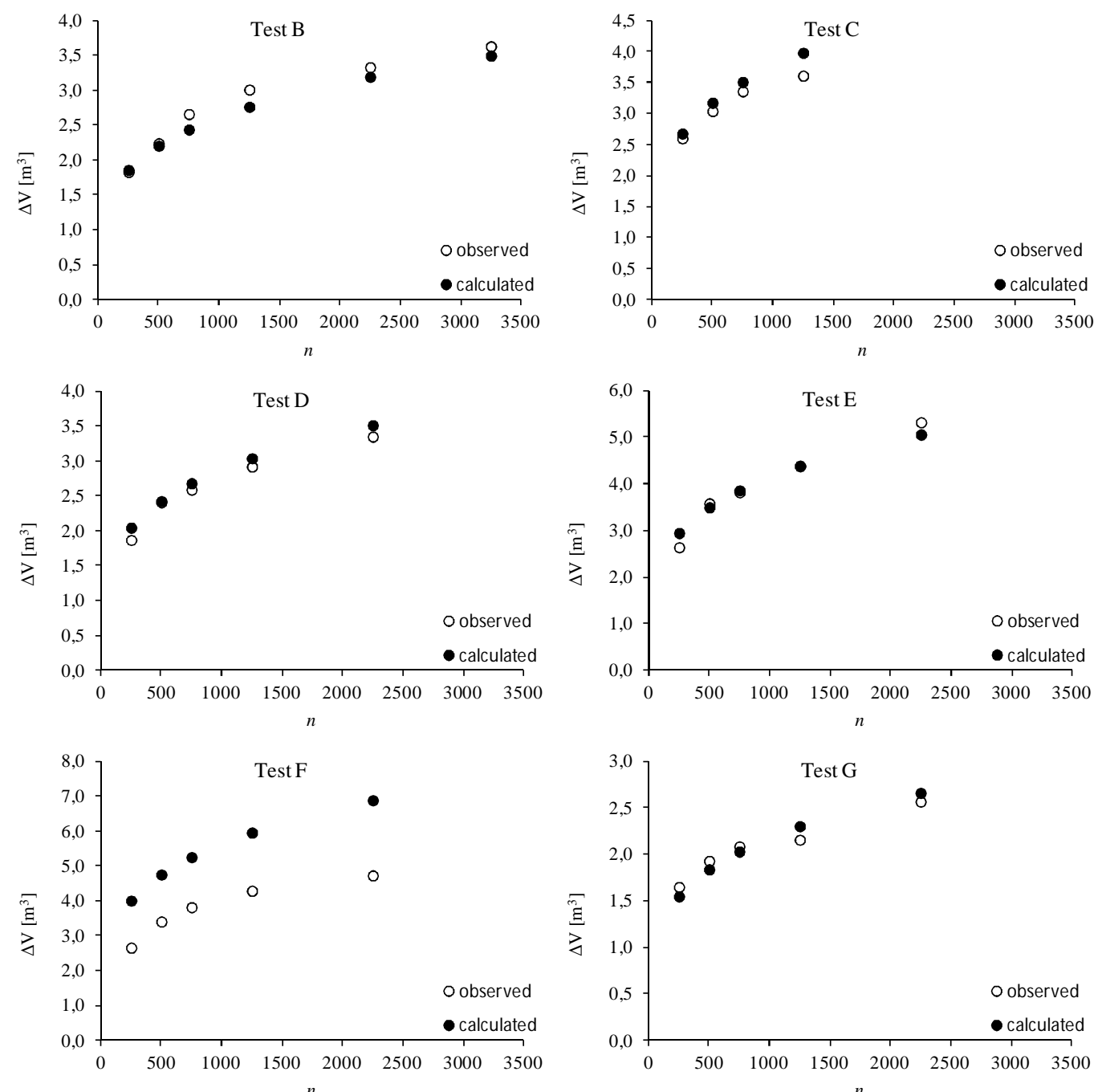

Figure 6. Comparisons between (०) observed and $(\bullet)$ calculated values of $\Delta V=f(n)$.

The largest scatter between observed and calculated values of $\Delta V=f(n)$ has been observed for the case of overwash conditions (Test F) due to the model limitations. Although the use of Eq. (13) compensates the shortcomings of the model proposed by Larson et al. (2004) in its original version, in 
order to predict the foreshore profile changes neglected by the analytical model, the use of a numerical model is needed.

\section{THE NUMERICAL MODEL C-SHORE}

Hydrodynamic modelling of the nearshore environment has reached a certain level of maturity over the past several decades as a result of well defined equations, established numerical solutions, and quality laboratory and field measurements. Modelling of sediment transport and beach profile evolution has not yet approached a similar level of accuracy. Most commonly applied models for shoreline and beach profile changes rely, at least partially, on empirical relationships to predict modifications. Some more recent approaches include a detailed physical basis, but are considerably more complex and demonstrate no greater skill (Johnson et al. 2009).

The adopted time-averaged numerical model C-SHORE (Kobayashi et al. 2007) has been under development during the past few years (Figlus et al. 2011), approaching a simple, practical and accurate code that predicts beach-dune profile evolution over the near-shore region in response to waves, currents and water levels. The combined wave and current model operates under the assumption of long-shore uniformity and includes the effects of a wave roller and quadratic bottom shear stress. The numerical integration of the depth-averaged energy, momentum, and continuity equations results in predictions of wave height, water level, and wave-induced steady currents. The model accounts for wave and current interaction, wave-related sediment transport, cross-shore bedload and suspended transport rates. The interested reader is referred to Kobayashi et al. (2007) for a detailed description of the model formulation.

\section{C-SHORE CALIBRATION AND VERIFICATION}

Data on the beach profile evolution have been used to calibrate and validate C-SHORE for the present experimental investigation. A selection of 6 representative tests were considered for the computations. The measured initial profile at time $t=0$ was adopted as input bathymetry; the horizontal coordinate $x^{\prime}$ is equal to zero at the end of the flat horizontal bottom $(x=21.70 \mathrm{~m})$. The model CSHORE (Kobayashi et al. 2007) was implemented with the current default values for the sediment transport coefficients, where only the breaking efficiency parameter, $e_{\mathrm{B}}$, was changed from 0.005 to 0.01. In fact, as expected for energetic storm wave conditions, where suspended load dominates the transport, the profile evolution is strongly influenced by the efficiency due to wave breaking. Increasing $e_{\mathrm{B}}$ to 0.01 effectively increases the suspension due to the wave dissipation. The breaking model in C-SHORE relies on a user-specified $\gamma^{\prime}$, the ratio of wave height to water depth in the saturated breaking region (Battjes and Stive 1985, Kobayashi et al. 2009). In this case, the beach profiles were modelled using $\gamma^{\prime}=0.7$. The other parameters had a relatively small effect on the predicted profile and no systematic improvement was realized with departure from the defaults (Tomasicchio et al. 2011a, Tomasicchio et al. 2001b).

Figure 7 shows the C-SHORE predictions along with initial and final measured profiles at the end of the wave attacks. In general, the comparisons showed a good agreement between measured and computed beach-dune profiles. In accordance to the laboratory observations, the profile modification due to the wave action occurred very quickly during the first 250 waves run in each test. The foredune geometry changed through scarping and slumping, resulting in predominantly offshore sediment transport. The eroded sand, however, remained within the region of major profile change, creating a more gently-sloping nearshore profile with a bar/step where intense wave breaking occurred. Test F and Test I presented more evident scatters between physical observations and numerical results. In particular, in the case of Test I (Figure 7 (f)), overtopping waves already started to significantly erode the backdune during the first 250 waves. Dune erosion and overwash proceeded to lower and destroy the entire dune very quickly until the dune breaching occurred. During the phase of overwash, the increased back-dune erosion, due to increased wave overtopping, resulted in apparent onshore migration of the lowered dune crest until the formation of an horizontal platform in substituting the concave beach. In this case, it has to be considered that overwash deposition landward of the dune is affected by the experimental set-up. Moreover, it should be considered that the adopted numerical model CSHORE (Kobayashi et al. 2007) was developed to predict berm and dune erosion in the absence of overtopping and, consequently, in the present version adopted, cannot predict accurately the sediment accretion landward of the dune crest around the cross-shore location $x^{\prime}=46 \mathrm{~m}$ due to the major overwash event. 

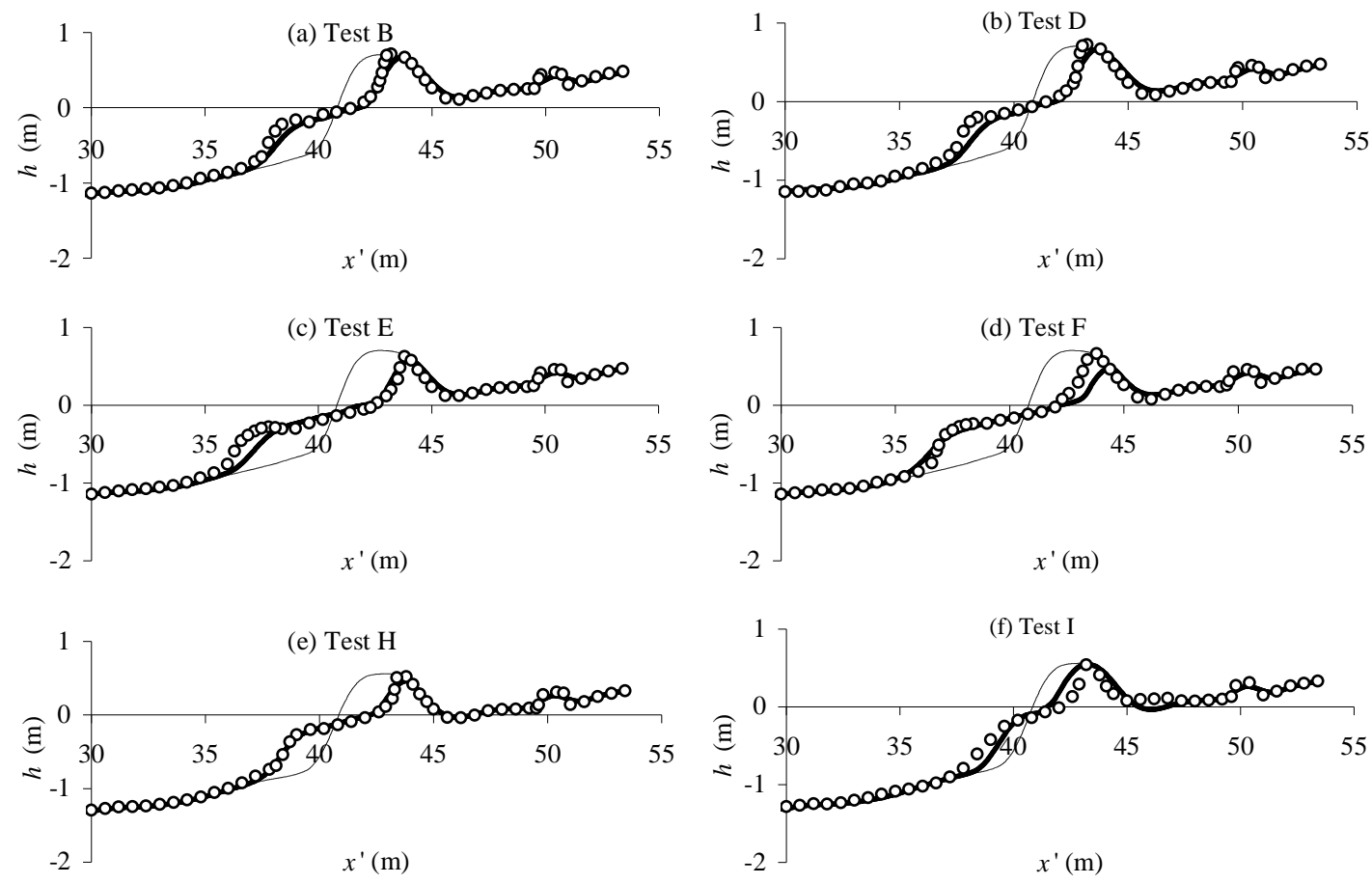

Figure 7. Comparisons between (o) observed, (-) computed and (-) initial beach-dune profiles.

\section{CONCLUSIONS}

High-quality data sets from large scale laboratory experiments (hydrodynamics, sediment transport, overtopping, overwash, photogrammetric survey, mechanical bed profile survey) have been carried out at LIM/UPC in Barcelona within the EU-funded Hydralab III project.

The occurrence of 3 different dune erosion regimes (Sallenger et al. 2003), collision, overwash and breaching, under different water levels and wave conditions has been observed during the physical model tests.

The research activity has fulfilled the following principal purposes: to observe the time variation of the dune profile under a given wave attack and to investigate its dependency on wave height, wave period and storm surge level.

As expected, the experiments showed that $\Delta V=f(n)$ and $\Delta x=f(n)$ present a different behaviour for the two intervals: $n<500$ and $n>500$, respectively; in particular, the larger values of $\Delta x$ have been observed during the first wave attack whit $n=250$; in this case, a percentage (\%) of dune recession distance in the range between 22.5 to 52.5 has been obtained. Based on the analysis of the test results, the effects of $T_{\mathrm{p}}$ and $h_{0}$ on dune erosion in terms of $\Delta V$ and $\Delta x$ appeared evident; in particular, $\Delta V$ and $\Delta x$ increase for larger values of $T_{\mathrm{p}}$ in accordance with van Gent et al. (2008) and $h_{0}$, which correspond to overwash conditions.

The analytical model proposed by Larson et al. (2004) in a simplified version has been calibrated and verified for the preliminary estimates of $\Delta V=f(n)$; the comparison between observed values and calculated results showed a good agreement; the larger scatters have been obtained for the case of overwash condition (Test F) due to the model limitations.

Experimental data on beach profile evolution have been used to calibrate and validate the numerical model C-SHORE (Kobayashi et al. 2007). The model is shown to predict the foreshore and dune profile evolution with reasonable accuracy in case of collision regime with minor overwash. The comparison between the measured and computed dune profile, landward of the dune crest, appears poor when a combination of strong overtopping-overwash conditions occurred. 


\section{ACKNOWLEDGMENTS}

The present research has been supported by the European Community's Sixth Framework Programme (FP6) through the grant to the budget of the Integrated Infrastructure Initiative HYDRALAB III within the Transnational Access Activities, Contract no. 022441.

It has been also partly funded by the Italian Minister of University and Research (PRIN 2008 "Strumenti operativi per la stima della vulnerabilità dei litorali sabbiosi anche in presenza di strutture costiere").

The Authors gratefully acknowledge prof. Nobuhisa Kobayashi from University of Delaware for the fruitful discussion and comments.

\section{REFERENCES}

Battjes, J.A., and Stive, M.J.F. 1985. Calibration and verification of a dissipation model for random breaking waves. Journal of Geophysical Research, 90 (C5) 9159-9167.

D'Alessandro, F., Tomasicchio, G.R. 2008. The BCI criterion for the initiation of breaking process in Boussinesq-type equations wave models. Coastal Engineering, (55) 1174-1184.

Delft Hydraulics 1982a. Dune erosion during an extreme storm surge, Noorderstrand Schouwen. Research report $M 1797$.

Delft Hydraulics 1982b. Dune erosion at the hotels 'La Specia' en 'De blanke top' in Zeeuwsch Vlaanderen. Research report $M 1811$.

Delft Hydraulics 1984a. Scale series on dune erosion, large scale tests in the Delta Flume. Research report M1263, part III.

Delft Hydraulics 1984 b. Dune erosion due to design storm surge at Walcheren, Golflinks en Vijgeter, investigation of stability and effect of the dune revetments. Research report M1958.

Delft Hydraulics 1987. Systematic research on the effectiveness of dune toe revetments, large scale model investigations. Research report $H 298$, part I.

Delft Hydraulics 2004. Model study of dune erosion: experimental results of small scale pilot tests (in Dutch), Report H4265, Delft, The Netherlands.

Delft Hydraulics 2006. Dune erosion, large-scale model tests and dune erosion prediction method, Report H4357, Delft, The Netherlands.

Delft Hydraulics 2007. Technical Report Dune Erosion (in Dutch), Report H4357, Delft, The Netherlands.

Dette, H.H., Peters, K., Newe, J. 1998. Large wave flume experiments '96/97, experiments on beach and dune stability. Rep. No. 830, Leichtweiss Inst., Tech. Univ. Braunschweig.

Donnelly, C., Kraus, N.C., Larson, M. 2006. State of knowledge on measurement and modeling of coastal overwash, Journal of Coastal Research, 22(4), 965-991, West Palm Beach, Florida.

Emanuel, K., Sundararajan, R., Williams, J. 2008. Hurricanes and global warming: results from downscaling IPCC AR4 simulations. Bulletin of the American Meteorological Society, 89 (3), 347-367.

Figlus, J., Kobayashi, N., Gralher, C., Iranzo, V. 2011. Wave overtopping and overwash of dunes. Journal of Waterway, Port, Coastal and Ocean Engineering, ASCE, 137(1), 26-33.

Fisher, J.S., Overton, M.F., Chisholm, T., 1986. Field measurements of dune erosion, Proceedings of the 20th Coastal Engineering Conference, ASCE, pp. 1107- 1115.

Johnson, B.D., Gravens, M., Wamsley, T., Kobayashi, N. 2009. A predictive model for beach profile evolution. Proc. of Coastal Dynamics 2009, 1-9, World Scientific.

Hancock, M.W. 1994. Experiments on irregular wave overtopping and overwash of dunes, Master Thesis, Department of Civil Engineering, University of Delaware, Newark, Delaware.

Hancock, M.W., Kobayashi, N. 1994. Wave overtopping and sediment transport over dunes, Proc. $24^{\text {th }}$ International Conference on Coastal Engineering, 2028-2042, Kobe, Japan, ASCE.

Hunt, I.A., 1959. Design of seawalls and breakwaters. Journal of the Waterways and Harbors Division, 85, 123-152.

Kobayashi, N., Tega, Y., and Hancock, M.W. 1996. Wave reflection and overwash of dunes, Journal of Waterway, Port, Coastal and Ocean Engineering, ASCE, 122(3), 150-153.

Kobayashi, N., Agarwal, A., and Johnson, B.D. 2007. Longshore current and sediment transport on beaches, Journal of Waterway, Port, Coastal and Ocean Engineering, ASCE, 133(4), 296-306.

Kobayashi, N, Buck, M., Payo, A., and Johnson, B.D. 2009. Berm and dune erosion during a storm, Journal of Waterway, Port, Coastal and Ocean Engineering, ASCE, vol. 135 (1), 1-10. 
Kraus, N.C., Smith, J.M. 1994. Supertank laboratory data collection project. Technical Report CERC 94-3, U.S. Army Engineers Waterways Experiment Station, Coastal Eng. Research Center, Vicksburg, USA.

Larson, M., Erikson, L., Hanson, H. 2004. An analytical model to predict dune erosion due to wave impact. Coastal Engineering, (51) 675-696.

Nishi, R., Kraus, N.C., 1996. Mechanism and calculation of sand dune erosion by storms, Proceedings of the 25th Coastal Engineering Conference, ASCE, pp. 3034-3047.

Overton, M.F., Fisher, J.S., Fenaish, T., 1987. Numerical analysis of swash forces on dunes. Proceedings of Coastal Sediments '87, ASCE, pp. 632-641.

Sallenger, A.H., Howd, P., Stockdon, H., Guy, K., Morgan, K.L.M. (2003). On predicting storm induced coastal change, Proc. Coastal Sediments, Clearwater Beach, Florida, USA.

Tomasicchio, G.R. 2004. Surface roller of breaking waves at barred beaches. Journal of Coastal Research, SI 39, pp. 875-879.

Tomasicchio, G.R., Sanchez Arcilla, A., D’Alessandro, F., Ilic, S., James, M., Fortes, C.J.E.M., Sancho, F., Schüttrumpf, H. 2011a. Large-scale flume experiments on dune erosion processes. Journal of Hydraulic Research, Vol. 49, No. S1, pp. 20-30.

Tomasicchio, G.R., D’Alessandro, F., Barbaro G. 2011b. Composite modelling for large-scale experiments on wave-dune interactions. Journal of Hydraulic Research, Vol. 49, No. S1, pp. 15-19.

USACE, US Army Corps of Engineers 2003. Coastal Engineering Manual, Part. V. Coastal and Hydraulics Lab., U.S. Army Engineer Research and Development Center, Vicksburg, Mississippi, USA.

van Gent, M.R.A., van Thiel de Vries, J.S.M., Coeveld, E.M., de Vroeg, J.H., van de Graaff, J. 2008. Large-scale dune erosion tests to study the influence of wave periods. Coastal Engineering, (55) 1041-1051.

van Thiel de Vries, J.S.M., van Gent, M.R.A., Walstra, D.J.R., Reniers, A.J.H.M. 2008. Analysis of dune erosion processes in large-scale flume experiments. Coastal Engineering, (55) 1028-1040.

Vellinga, P. 1986. Beach and dune erosion during storm surges, Doctoral Thesis, Delft University of Technology, Delft, The Netherlands (Publication 372, Delft Hydraulics). 